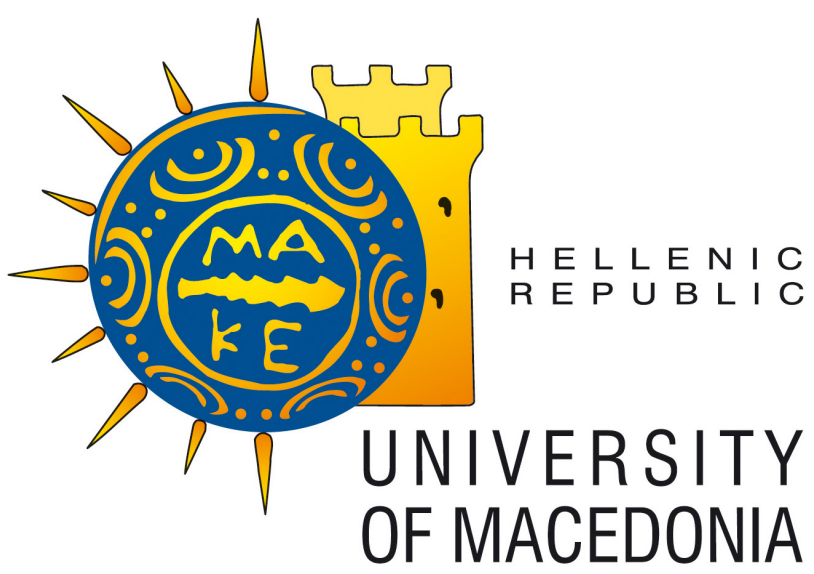

ISSN 1791-3144

\author{
University of Macedonia \\ Department of Economics
}

Discussion Paper Series

Economists, research performance and national inbreeding: North versus South

Stelios Katranidis, Theodore Panagiotidis and Costas Zontanos

Discussion Paper No. 1/2016

Department of Economics, University of Macedonia, 156 Egnatia str, 54006 Thessaloniki,

Greece, Fax: + 30 (0) 2310891292

http://www.uom.gr/index.php?newlang=eng\&tmima=3\&categorymenu=2 


\title{
Economists, research performance and national inbreeding: North versus South
}

\author{
Stelios Katranidis \\ Department of Economics \\ University of Macedonia \\ Greece \\ katranid@uom.gr
}

\author{
Theodore Panagiotidis \\ Department of Economics \\ University of Macedonia \\ Greece \\ tpanag@uom.edu.gr
}

\author{
Costas Zontanos \\ University of Macedonia \\ Greece \\ zontanos@uom.gr
}

April 2016

\begin{abstract}
We investigate the research performance of 404 economists working in 17 Economics Departments and 4 countries. Two countries from the North of Europe (Belgium and Denmark) are compared with two countries from the South (Greece and Portugal) in terms of research productivity. Their performance is ranked using bibliometric indices. We examine the factors that drive economist's research performance using OLS and quantile regression analysis. The most productive economists have a US PhD and work in the North. Inbreeding at the national level is associated with higher productivity in the North and lower in the South.
\end{abstract}

Keywords: Economics, ranking,

JEL Classification: A11, A12, D63,

Acknowledgments: We would like to thank two anonymous referees, Andrew Oswald and the participants of the $14^{\text {th }}$ International Society of Scientometrics and Infometrics conference for useful comments. 
"It would be of interest to determine, if possible, the part which men of different calibre contribute to the progress of science" Alfred J. Lotka 1926

\section{Introduction}

The importance of knowledge (and research) and its "public good" characteristics was highlighted in economics early on by Nelson (1959) and Arrow (1962). In the latter, Arrow argues that scientific knowledge is a public good and "for optimal allocation to invention it would be necessary for the government or some other agency not governed by profit-and-loss criteria to finance research". Merton (1957) point out that the goal of scientists is to establish "the priority of discovery". The importance of this public good (research, knowledge) leads to the need to examine thoroughly the productivity of researchers. In another strand of the literature, Lotka (1926) was the first one to quantify scientific work. The name index of two journals was examined for assessing scientists' research performance. This seminal study has opened the way to a literature that measures and compares scientific output and productivity.

Over the last decade the interest on ranking researchers, faculty members, departments, universities and scientific journals has increased. Simultaneously, attempts are made to assess research output as part of various research exercises that were carried out across Europe (RAE in the UK, see Clerides et al 2011 for the UK and the relevant report of the European Commission ${ }^{1}$ ). This is evident from the increase in publications on the topic (see Carrasco and Ruiz-Castillo (2014) for a detailed discussion on the productivity of economists). In this literature, three issues that have emerged include (i) the characteristics of the databases employed, (ii) the ranking criteria and (iii) the bibliometric indices. They usually lead to classifications and rankings of individuals, departments and universities. Only few studies have made the additional step and examine the factors that drive productivity differentials. This study belongs to this group.

\footnotetext{
1 The report is available here: https://ec.europa.eu/research/science-society/document_library/pdf_06/assessing-europeuniversity-based-research_en.pdf.
} 
This paper examines the research determinants of the research output of - 404 economists - faculty members from 17 European Economics Departments; 8 of them in Belgium, 2 in Denmark, 3 in Portugal and 4 in Greece. In contrast to the literature we examine the drivers of productivity and relax the symmetry assumption in a setting that allows independent variables to affect highly productive economists in a different way to (relative) low productivity economists. The contribution of this study is as follows: first, by adopting alternative productivity indicators, we rank research in the four countries. Second, we investigate the determinants of scientific output and demonstrate that the country of doctoral studies $(\mathrm{PhD})$ affects research performance. Third, we examine the relation between the country of affiliation and research productivity in the four countries. Forth, we compare the determinants of research performance at the two tails of the distribution (relative highly productive economist's vs relative low).

This paper has four parts. In section 2 we review the literature on academic ranking and research productivity. Section 3 provides the descriptive statistics and the bibliometric indices for each country. Section 4 discusses the results of the regression analysis and section 5 concludes.

\section{Literature review}

The literature on research evaluation and academic ranking has expanded recently. The data that are typically employed are based on the number of papers published in international refereed academic journals and their corresponding citations ${ }^{2}$. The former are recognized as the main outlet of scientific work in economics. Many of these studies assess the quality of the papers via the journals' academic status (Combes, \& Linnemer, 2003; Kalaitzidakis et al. 2003; Kalaitzidakis et al. 2011). The underlying logic is that a paper is as good as the journal that was published. Attempts of this kind, i.e. evaluation and rankings of

\footnotetext{
2 Although most studies in the area are empirical, Goudard and Lubrano (2013) in a theoretical model introduce social capital as a necessary complement to explain the creation of scientific human capital.
} 
European economists and economic institutions based on this (indirect) method, include Kalaitzidakis et al. (1999) on Greek university departments, Guimarães (2002) on Portuguese, Bauwens (2003) on Belgian, Çokgezen (2006) on Turkish faculty and universities and Lubrano et al (2003) who compared faculties and universities research performance among 18 different European countries. The problem with this approach is that it relies on the perceived status of the journal and not on the impact of the paper. Oswald (2007) argues on the issue: "if the criterion is intellectual impact measured by citations, in this sample it was better to publish the top article in an issue of the Oxford Bulletin of Economics and Statistics than to publish all of the bottom-four papers in an issue of the American Economic Review". ' On the other hand, more recently published papers, as those on Ireland (Ruan, \& Tol, 2008; Tol, 2008), on Israel (Ben-David, 2010), on Sweden (Henkerson, \& Waldenström, 2011) and on Greece (Katranidis et al 2014) rely on bibliometric databases (Web of Science, Google Scholar and Scopus) and consider directly the scientific impact of each paper separately, i.e. according to how many times it has been cited by other researchers. The advantage of this approach is that it looks directly at the merit of the paper (via its citations) rather than the "perceived" merit of the journal.

Furthermore, some of the above papers proceed further in an attempt to examine the determinants of research performance; for example, regarding discrepancies in research performance between private and state universities (Çokgezen, 2006), high and low rank academic positions (Ben-David, 2010) and differences in academic advancements due to the country where the doctoral studies have been completed (Guimarães, 2002; Katranidis et al 2014). None of the above studies compares research performance between countries nor does it assess how $\mathrm{PhD}$ location affects the productivity of a researcher. We aim to fill this gap by comparing how common characteristics of researchers (US PhD for instance) can affect the productivity of economists working in different countries.

\footnotetext{
${ }^{3}$ Leydesdorff (2008) questions whether journal and journal rankings are suitable for research evaluation. He also reminds us that Garfield's $(1972,1979)$ initial purpose when creating the impact factor and the Journal Citation Reports was not to evaluate research but journals".
} 
In this strand of this literature, factors that could affect research performance include: (i) academic inbreeding, (ii) the place and the university where the doctoral studies were completed, and (iii) the department where the faculty member is employed, and (iv) these factors in combination with the time that has elapsed since completing the doctoral studies (Long, 1978; Long, Bowers, Barnett, \& White, 1998). This time is usually referred to as academic age (length of academic life).

The importance of the country of $\mathrm{PhD}$ studies can be justified as follows: productive academics in terms of both quantity and quality are more likely to have graduated from "highstatus" Universities/schools/departments. This can be attributed to more than one reasons: first, "high-status" universities usually attract the best doctoral candidates (D'Aveni, 1996; Jacobs, Hartgraves, \& Beard, 1986). Second, these academic institutions are characterised by high quality research environment, more resources, increased opportunities and increased pressure for more and better research performance. Third, these are schools where one can meet influential scholars and reviewers and get access to scientific networks, groups, editorial boards and journal editors; these contacts often can be very important in research. "Highstatus" schools are more likely to provide better opportunities in terms of funding, conference participation, collegial interaction and spill overs and generally a more competitive research environment. Kalaitzidakis et al (2004) employ survey data and find evidence that European economics departments with North-American links have higher research output. Bauwens et al (2011) highlight the importance of English proficiency for research productivity amongst economists. Kahn and MacGarvie (2016) discuss the dominant role of the US in research. In particular in terms of the number of doctorates and also being home to a disproportionate share of top scientists.

In this paper, we examine whether all the above arguments not only apply at the departmental level but could also be present at a higher aggregation level, i.e. they might characterise the educational system of a country overall. For this reason, we examine whether 
a scientist's research productivity is influenced by the educational system of the country of doctoral studies and compare productivity of US trained economists with the ones that were trained at home.

Another factor that could influence research productivity is academic inbreeding. The practice of employing $\mathrm{PhDs}$ by the Universities that trained them is referred to as "academic inbreeding". Horta et al (2010) demonstrated that it is damaging scholarly output. The latter is also supported by Inanc and Tuncer (2011). In this study we are going to employ this term in a wider form by comparing the productivity of economists with US PhDs with those that are trained locally (inbreeding at the national level ${ }^{4}$ ). Additionally, it has been demonstrated that academic affiliation is an influential factor regarding research performance (D'Aveni, 1996). Next, we assume, that these special characteristics of different departments are also reflected in the national average. This may hold especially in our case, since in Europe and at least in comparison with the U.S., the variability across the university departments of the same country is limited. Additionally academic salaries within a country are not that different.

\section{Data}

Our dataset includes 404 faculty members (economists) from 17 departments and 4 countries. We have chosen two relative small (and thus comparable) countries from the north (Belgium and Denmark) and two from the south (Greece and Portugal). The sample size was determined using two criteria: (a) at the national level the overall sample size represents $25 \%$ of the RePEc (http://repec.org/) registered economists, (b) we collected data from economists that were affiliated to the highest ranked departments until reaching the

\footnotetext{
${ }^{4}$ One hypothesis could be that they would not have access to the intense academic environment and the knowledge spill overs that the US universities can offer.
} 
designated ceiling $(25 \% \text { of RePEc registered economists })^{5}$. The departments under consideration are listed in Table 1.

Table 1 here

The following bibliometric indices were calculated: productivity (number of publications per faculty); overall impact (number of citation per faculty) and the rational $b^{*}$ index as it has been initially proposed by Hirsch (2005) and modified by Tol (2008). All of them were divided by the research age, i.e. the number of years after the completion of the $\mathrm{PhD}$ studies. These indices are lightening several aspects of what is refereed in the literature as research performance.

We proceed the analysis at the individual level. ${ }^{6}$ The analysis for each faculty member of the seventeen economics departments under consideration is based on data retrieved from Scopus (March-May 2012). The faculty members have been identified according to the Website of each department (only economists have been considered). Data on the research work of each faculty member (number of papers, number of citations, and $b^{*}$-index) were collected from the Scopus citation database.

\section{Descriptive Statistics}

In this section we examine the characteristics of the sample of economists under examination. Table 2 presents the average research age, the percentage distribution of faculty members according to the country they completed their doctoral studies and the total number of faculty members per country. The youngest (average research age) faculty is employed in Portugal, followed by Denmark and Belgium. Greece has the oldest faculty. It is worth

\footnotetext{
5 The collection of data started from the top department in each country (as ranked by RePEc). The data collection would end when $25 \%$ of the registered (in RePEc) economics in each country would have included in the sample.

${ }^{6}$ Leydesdorff (2008) also argues that institutions are the wrong units of analysis for scientometric comparisons because of their heterogeneity.
} 
mentioning the very low percentage of Greek faculty members that have completed their $\mathrm{PhD}$ studies in their own country (we refer to this as national inbreeding). Moreover, a large part of Greek faculty, almost like their Portuguese colleagues, has completed their studies abroad, mainly in the UK and $\mathrm{US}^{7}$. These rates (for $\mathrm{PhD}$ in the UK) are considerably lower and almost negligible for the Belgian and Danish faculty members. Overall, in the north (Belgium and Denmark) most of the faculty is trained within the country $(69.77 \%$ and $66.1 \%$ respectively) whereas in the south the majority is trained abroad (81.71\% for Greece and $51.02 \%$ for Portugal).

Table 2 and 3 here

We also rank the productivity of economists from the four countries based on the three bibliometric indices. Table 3 presents the research performance depending on the place of completing the doctorate studies (PhD origin) and the country of employment (affiliation). All the presented mean values refer to Huber's $m$-estimator calculated using the Excel Add-in RobStat.xla available from the Royal Society of Chemistry (2002). According, to the first criterion $(p / f$ : papers per faculty and per year), a faculty member in Belgium has an average of 0.61 when she holds a Belgian $\mathrm{PhD}, 0.95$ when her $\mathrm{PhD}$ is from another European country and 0.70 when her $\mathrm{PhD}$ is from the US. There are no significant deviations for economists based in Denmark regarding differences in the $\mathrm{PhD}$ origin. The opposite holds for Greece and Portugal for economists trained either in the UK or (even more) overseas. Additionally, we observe that a faculty member holding a $\mathrm{PhD}$ from overseas scores differently in terms of papers per faculty and per year, with Belgium (0.70), Denmark (0.64), Greece (0.58) and Portugal (0.36). These differences regarding $\mathrm{PhD}$ origin are more distinct when productivity is measured by citations per faculty and per year $(c / f)$. For example when we examine the case of Belgium we observe an increase from 3.64, when the $\mathrm{PhD}$ studies have been completed in

\footnotetext{
${ }^{7}$ There is negligible number of Canadian $\mathrm{PhD}$ that is included in the US variable).
} 
Belgium to 5.69 if completed in another European country and even more when the studies have been completed overseas (7.82). These differences become even more distinct in the cases of Greece and Portugal. In the case of Greece (Portugal) $c / f$ increases from $0.58(0.33)$ for a local PhD to 3.41 (1.84) for a US PhD.

$H$-index divided by the years after the completion of the $\mathrm{PhD}\left(b^{*}\right)$ confirms the above mentioned results. For example a Greek (Portugese) faculty with a US $\mathrm{PhD}$ has an $b^{*}$-index equal to 0.24 (0.17) while the corresponding value for a Greek (Portugese) PhD holder is 0.12 (0.09). In contrast to the heterogeneity we observe in the south, there are no substantial differences for Belgian and Danish faculty members.

The highest productivity among PhD holders from Europe and the US is found in economists based in Belgium. The highest productivity among economists that complete their $\mathrm{PhD}$ studies in their country (what we refer to as national inbreeding) is found in Denmark based economists.

Overall differences according to $\mathrm{PhD}$ origin are more important for Greece and Portugal. Furthermore, the significant role of affiliation also emerges. The research performance of faculty with a PhD from overseas although comparable between Belgium and Denmark is always higher when we compare it with the two South-European countries, i.e. research performance decreases when the affiliation is in Greece and even more when in Portugal.

\section{Methodology}

In this section we make the further step and examine the factors that drive the research performance of an economist. There are two important factors that require further examination. On the one hand, we have the place that her $\mathrm{PhD}$ studies took place as a proxy of the training and the research culture of the researcher (factor one: research training). On the other, we want to examine the impact of the working environment on research 
performance. The research culture of the department, the interaction with his/her colleagues, the peer pressure, access to funding and the quality of the research seminars (knowledge spill overs) are all factors that can influence the research performance of a scientist (factor two: work environment).

The adopted specification allows us to make at least three comparisons: (i) examine whether research productivity varies according to whether the $\mathrm{PhD}$ was completed in the US, (ii) compare the productivity of economists with a US PhD and currently are employed in one of the four different countries under consideration and (iii) compare the productivity among inbred (at the national level) faculty. As a result the econometric specification we employ can be written as follows:

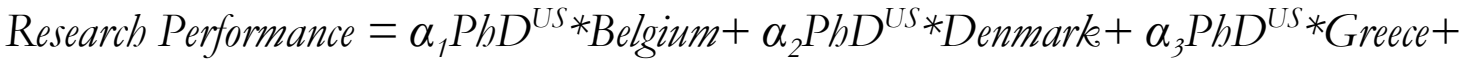

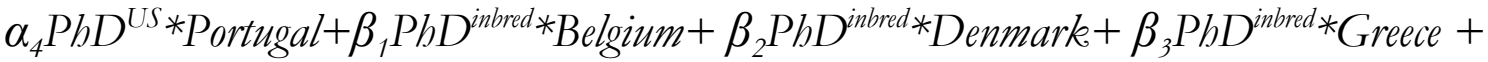

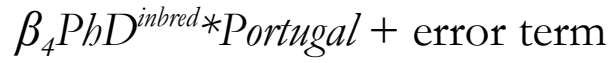

where Research Performance can be either (i) Papers per faculty per year or (ii) Citations per faculty per year. $\mathrm{PhD}^{\mathrm{US}}$ is a dummy variable that takes the value of 1 if $\mathrm{PhD}$ studies were completed in the US. Belgium, Denmark, Greece and Portugal are all dummy variables for the country that the researcher is currently employed and $P b D^{\text {inbred }}$ takes the value of 1 if the researcher completed their $\mathrm{PhD}$ from the same country that he/she is employed (inbreeding at the national level).

Equation 1 would be estimated using three alternative methodologies. We will employ OLS as a benchmark in order to obtain the average (linear) response. Additionally, we will employ the $M$-estimator proposed by Huber (1973) as this is considered useful in cases where the dependent variable contains outliers. Both the OLS and the $M$-estimator cannot take into

\footnotetext{
8 The $h$-index was also considered. The results were not qualitatively different to the ones we report.
} 
account asymmetries that might exist in the relationship. In other word they assume that the drivers of productivity affect in a symmetric way both (relative) high and low productivity economists. In order to relax the assumption of symmetry, we also consider the quantile regression (QR) introduced by Koenker and Bassett (1978) that estimates the conditional quantile response of the dependent variable given the covariates. QR estimators are more efficient compared to OLS ones when the errors are not normally distributed. They are also robust when outliers are present in the data. Last but not least, a QR estimate can be employed to quantify the sensitivity of the dependent variable to changes in the covariates at different points of the conditional distribution. In other words, it would allow us to identify the determinants of research performance both for the very productive and for those who are not that productive (model the entire distribution of productivity).

The purpose of this study is twofold; compare $\alpha_{1}$ to $\alpha_{2}, \alpha_{3}$ or $\alpha_{4}$ and compare $\alpha_{1}$, with $\beta_{1}, \alpha_{2}$ with $\beta_{2}$ etc. If $\alpha_{1}+\alpha_{2}>\alpha_{3}+\alpha_{4}$, the working environment in the north (Belgium and Denmark) is superior to the one in the south (Greece and Portugal) given that the researcher has a similar training ( $\mathrm{PhD}$ from the US). Additionally we would like to examine and compare coefficients $\beta_{1}, \beta_{2}, \beta_{3}$ and $\beta_{4}$. These parameters quantify the effect of national inbreeding. Their estimates would allow us to compare inbred faculty in the north with the ones in the south and assess whether inbreeding (at the national level) has a negative impact for the productivity of a researcher. If $\beta_{1}+\beta_{2}>\beta_{3}+\beta_{4}$ then the inbred faculty in the north is more productive than the inbred faculty in the south.

\section{Results}

Table 4 here

In this section we provide estimates for equation 1 . We are interested in both the average response (OLS) and the median response (quantile regression). Table 4 presents the 
results for the two alternative specifications of the research performance (one with papers per faculty per year as dependent variable and one with citations per faculty per year). For the first specification, where the depended variable is the papers per faculty per year, we observe that all coefficients (both the $\alpha$ 's and the $\beta$ 's) are positive and statistically significant at the $5 \%$ level (t-stats below each coefficient). The relative productivity ranking that emerges (based on the estimated coefficients of Table 4) for the US PhD holders is: Belgium, Greece, Denmark and Portugal and for the inbred PhD holders: Denmark, Belgium, Portugal and Greece. For the papers per year per faculty, it emerges that for someone with a $\mathrm{PhD}$ from the US the average performance per year is 0.957 if currently working in Belgium, 0.889 in Greece, 0.618 in Denmark and 0.452 in Portugal. For the citations per year: 11.9 if one holds a US $\mathrm{PhD}$ and works in Belgium, 5.12 in Greece, 4.18 in Denmark and 3.5 in Portugal.

With regard to the comparison between north vs south: $\hat{\alpha}_{1}+\hat{\alpha}_{2}=0.957+0.618=$ $1.575>1.341=0.889+0.452=\hat{\alpha}_{3}+\hat{\alpha}_{4}$. The latter implies that the working environment in the north stimulates research more compared to the south but this difference is not statistically significant ( $p$-value 0.6$)$. With regard to inbreeding: $\hat{\beta}_{1}+\hat{\beta}_{2}=0.81+0.94=1.75>$ $\hat{\beta}_{3}+\hat{\beta}_{4}=0.45+0.51=0.96$. The latter implies that inbred faculty in the north is considerable more productive than inbred faculty in the south. This difference is statistically significant $(p-$ value 0.008).

These results are not qualitatively different when we consider alternative measures of research performance (results available upon request). The $M$-estimation coefficients (useful when outliers are present) are also presented in Table 4 and confirm the OLS ranking for the US PhD holders (Belgium, Greece, Denmark and Portugal). However for the inbred PhD holders only the coefficient for Denmark and Belgium is found to be significant (dependent variable citations per year). The latter suggests that inbreeding is associated with higher productivity in the north but not in the south. 
The analysis so far focused on the average researcher. However, it might be more informative to look at the median researcher as this is more representative. In order to do this we employ quantile regression $(\mathrm{QR})$ that investigates the median response rather than the average response (OLS) (see for instance Koenker, \& Bassett, 1978). This methodology relaxes the assumption of symmetry and examines the behaviour of the depend variable (research performance) in the entire conditional distribution. In other words this framework allows us to consider the determinants of both high and low productive researchers and not just the average researcher (OLS). The results for this econometric approach can be found in Table 4. Both $M$-estimation and QR reveal that inbreeding is different in the North compared to the South. Internal $\mathrm{PhD}$ holders in Belgium and Denmark are performing better than Greek and Portuguese economists with a $\mathrm{PhD}$ from the US. Inbreeding seems to be positive in the north and negative in the south.

\section{Table 5 and Figure 1}

The research productivity as it is measured by the alternative specifications is summarized in Table 5 where each coefficient is divided by the max coefficient. As it is evident from the entries in Table 5, the OLS estimates overestimate the research productivity of economists based in Greece and Portugal relative to the best (the best are researchers based in Belgium for US PhD holders and Denmark for local PhD holders). The quantile regression coefficients are lower compared to the OLS ones. The latter can be explained by the fact that the median researcher is more representative than the average one given the outliers that exist in these countries. The most notable difference emerges when one compares the productivity of the median researcher from Denmark with $\mathrm{PhD}$ from the same country and the median inbred researcher from Portugal (or Greece). We observe that the latter has only 4\% (or $6 \%$ in the case of Greece) of the citations of the median researcher from Denmark. Figures 1 and 4 visualise the differences between the researchers (based on the OLS estimates). It is obvious from the graph that (i) differences in productivity are smaller among US PhD holder and (ii) 
differences in research productivity are considerably bigger among researchers that completed their PhDs in the country they are working (Figure 4).

As noted, QR relaxes the assumption of symmetry. The results for various quintiles of the dependent variable (research productivity) together with their standard errors are presented in Figures 2 and 3 and in Table 4. It is clear from the evidence presented in these graphs that the factors that determine productivity are of increasing importance when one considers the most productive economists (right tail of the conditional distribution): Having a $\mathrm{PhD}$ from the US is more important for more productive economists (Figure 4).

Figures 3 and 4 here

\section{Concluding remarks}

This paper examines the research performance of 404 economists working in 17 Economics Department from 4 European countries. Comparisons are made between two countries from the North of Europe (Belgium and Denmark) with two countries from the South (Greece and Portugal).The analysis for the research performance of their faculty takes into account the country they completed their $\mathrm{PhD}$ studies on the one hand and their current (country) affiliation on the other. We provide a ranking of their research performance based on these two criteria. Economists based in Denmark have higher papers per faculty per year, citations per faculty per year and higher $b^{*}$ (Belgium scores a very close second). Furthermore, we identify the factors that drive the research performance by employing regression analysis and quantile regression analysis based on both $\mathrm{PhD}$ origins and current country affiliation. In terms of productivity (impact) the following order emerges: 1 (1) $\mathrm{PhD}$ from the US and works in Belgium, 2 (2) PhD from Denmark and works in Denmark, 3 (4) $\mathrm{PhD}$ from the US and works in Greece, 4 (3) PhD from Belgium and works in Belgium, 5 (5) 
$\mathrm{PhD}$ from the US and works in Denmark, 6 (7) PhD from Portugal and works in Portugal, 7 (8) PhD from Greece and works in Greece and 8 (6) PhD from the US and works in Portugal. A policy recommendation that can be derived from the analysis is that the research performance at the national level for countries like Greece and Portugal can significantly improve when their faculty complete their doctoral studies abroad. However Greek and Portuguese universities do not take full advantage of this incoming and highly enriched human capital compared to Belgium or Denmark. The importance of these factors is increasing once the symmetry assumption is relaxed. When quantile regression was employed, it was demonstrated that a US PhD was even more significant for more productive economists.

Last but not least inbreeding is a characteristic that affects research performance in a positive way only in the north. The median inbred faculty in Greece (Portugal) has only 6\% (4\%) of the citations per paper of the Danish one. 


\section{References}

Arrow, K. (1962) "Economic Welfare and the Allocation of Resources for Invention," in The Rate and Direction of Scientific Activity: Economic and Societal Factors, Cambridge, MA: NBER, $609-25$.

Bauwens, L. (2003, May 31). Economic research in Belgian universities. Retrieved from: http://www.core.ucl.ac.be/econometrics/Bauwens/rankings/rankings.htm

Bauwens, L., Mion, G. and Thisse, J. F., (2011), The Resistible Decline of European Science, Recherches économiques de Lowvain, 77, 4, 5-31.

Ben-David, D. (2010). Ranking Israel's economists, Scientometrics, 82, 351-364.

Carrasco R. \& J. Ruiz-Castillo, (2014), The Evolution Of The Scientific Productivity Of Highly Productive Economists," Economic Inquiry, 52(1), 1-16.

Clerides S. \& Pashardes P. \& Polycarpou A., (2011).Peer Review vs Metric-based Assessment: Testing for Bias in the RAE Ratings of UK Economics Departments, Economica, 78(311), 565-583.

Çokgezen, M. (2006). Publication performance of economists and economics departments in Turkey (1999-2003). Bulletin of Economic Research, 58, 253-265.

Combes, P.P. \& Linnemer, L. (2003). Where are the economists who publish? Publication concentration and rankings in Europe based on cumulative publications. Journal of the European Economic Association, 1, 1250-1308.

D’Aveni, R.A. (1996). A multiple-constituency, status-based approach to interorganizational mobility of faculty and input-output competition among top business schools. Organization Science, 7, 166-189.

Garfield, E. (1972). Citation analysis as a tool in journal evaluation. Science. 178(4060), 471-479.

Garfield, E. (1979). Citation indexing: Its theory and application in science, technology, and humanities. New York: John Wiley \& Sons.

Goudard, M. \& Lubrano M. (2013). Human capital, social capital and scientific research in Europe: An application of linear hierarchical models, Manchester School, 81, 876-903.

Guimarães, P. (2002). The state of Portuguese research in economics: An analysis based on publications in international journals. Portuguese Economic Journal, 1, 3-25. 
Henkerson, M., \& Waldenström, D. (2011). How should research performance be measured? A study of Swedish economists. Manchester School, 79, 1139-1156.

Hirsch, J.E. (2005). An index to quantify an individual's scientific research output. Proceedings of the National Academy of Sciences of the United States of America, 102, 16569-16572.

Horta, H., Veloso, F.M., Grediaga R. (2010). Navel gazing: Academic Inbreeding and scientific productivity, Management Science, 56, 414-429.

Huber, P.J. (1973) Robust regression: Asymptotics, Conjectures and Monte Carlo, The Annals of Statistics, 1, 799-821.

Inanc, O. Tuncer O. (2011). The effect of academic inbreeding on scientific effectiveness, Scientometrics, $88,885-898$.

Jacobs, F.A., Hartgraves, A.L., Beard, L.H. (1986). Publication productivity of doctoral alumni: A timeadjusted model. Accounting Review, 61, 179-187.

Kahn S. and MacGarvie M.J. (2016). How important is US location for research in science, forthcoming Review of Economics and Statistics.

Kalaitzidakis, P., Mamuneas T.P. Savvides, A. \& Stengos, T. (2004). Research spillovers among European and North-American economics departments, Economics of Education Review, 23, 191202.

Kalaitzidakis, P., Mamuneas, T.P., \& Stengos, T. (1999). Ranking of economics departments among Greek-speaking institutions. Economia, 3, 70-75.

Kalaitzidakis, P., Mamuneas, T.P., \& Stengos, T. (2003). Rankings in academic journals and institutions in economics. Journal of the European Economic Association, 1, 1346-1366.

Kalaitzidakis, P., Mamuneas, T.P., \& Stengos, T. (2011). An updated ranking of academic journals in economics. Canadian Journal of Economics, 44, 1525-1538.

Katranidis, S., Panagiotidis, T and Zontanos, C., (2014), An evaluation of the Greek universities' economics departments, Bulletin of Economic Research, 66, 173-182.

Koenker, R., \& Bassett, G. (1978). Regression quantiles. Econometrica, 46, 33-50.

Leydesdorff L. (2008), Caveats for the Use of Citation Indicators in Research and Journal Evaluations, Journal of the American Society for Information Science and Technology. 59(2), 278-287. 
Long, J.S. (1978). Productivity and academic position in the scientific career. American Sociological Review, 43, 889-908.

Long, R.G., Bowers, W.P., Barnett, T., \& White, M.C. (1998). Research productivity of graduates in management: Effects of academic origin and academic affiliation. Academy of Management Journal, 41, 704-714.

Lotka, A. (1926) “The Frequency Distribution of Scientific Productivity.” Journal of the Washington Academy of Sciences, 16, 317-23.

Lubrano, M., Bauwens, L., Kirman, A., \& Protopopescu, C. (2003). Ranking economics departments in Europe: A statistical approach. Journal of the European Economic Association, 1, 1367-1401.

Merton, R. K. (1957) "Priorities in Scientific Discovery: A Chapter in the Sociology of Science." American Sociological Review, 39, 663-71.

Nelson, R. (1959) “The Simple Economics of Basic Scientific Research.” Journal of Political Economy, 67, 297-306.

Oswald, A. (2007) “An Examination of the Reliability of Prestigious Scholarly Journals: Evidence and Implications for Decision-Makers.” Economica, 74, 21-31.

Royal Society of Chemistry. (2002). MS-Excel add-in for robust statistics (Version 1.0) [Software]. Available from: http://www.rsc.org/membership/networking/interestgroups/analytical/amc/

Ruan, F., \& Tol, R.S.J. (2008). Rational (successive) h-indices: An application to economics in the Republic of Ireland. Scientometrics, 75, 395-405.

software/RobustStatistics.asp

Tol, R.S.J. (2008). A rational, successive g-index applied to economics departments in Ireland. Journal of Informetrics, 2, 149-155. 


\section{Table 1: Departments per Country under consideration}

Belgium:

- École des Sciences Économiques de Louvain. Université Catholique de Louvain.

- Department of Economics. Faculteit Economie en Bedrijfswetenschappen. Katholieke Universiteit Leuven.

- European Centre for Advanced Research in Economics and Statistics (ECARES) \& Département d'Économie Appliquée (DULBEA). Solvay Brussels School of Economics and Management. Université Libre de Bruxelles.

- Economics Department. HEC École de Gestion. Université de Liège.

- Department of Economic Science. Faculté des Sciences Économiques, Sociales et de Gestion (FSESG). Facultés Universitaires Notre-Dame de la Paix (Namur).

- Dpts. General, Financial \& Social Economics. Faculteit Economie en Bedrijfskunde. Universiteit Gent.

- Dpt. Of Economics. Faculteit Toegepaste Economische Wetenschappen. Universiteit Antwerpen.

- Centre de Recherche en Économie (CEREC). Facultés Universitaires Saint-Louis.

Denmark:

- Institut for Økonomi, Aarhus Universitet.

- Københavns Universitet. Økonomisk Institut.

Greece:

- Department of Economics, Athens University of Economics and Business.

- Department of Economics, University of Crete.

- Department of Economics, University of Macedonia.

- Department of Economics, University of Piraeus.

Portugal:

- Universidade Nova de Lisboa, Faculdade de Economia.

- Instituto Superior de Economia e Gestão (ISEG), Department of Economics, Universidade Técnica de Lisboa.

- Grupo de Economia, Faculdade de Economia, Universidade do Porto. 
Table 2. Research age and faculty distribution according to the $\mathrm{PhD}$ origins in $\%$

\begin{tabular}{l|ccccccc}
\hline \hline Country & Research & \multicolumn{7}{c}{ PhD Origin in \% } & Faculty \\
\cline { 3 - 6 } & Age & $\begin{array}{c}\text { Dept. or } \\
\text { members }\end{array}$ & Inbred & Europe & UK & US & \\
Belgium & 18.01 & 50.39 & 19.38 & 13.18 & 2.33 & 14.73 & 129 \\
Denmark & 16.05 & 59.32 & 6.78 & 18.64 & 1.69 & 13.56 & 59 \\
Greece & 20.22 & 9.75 & 8.54 & 10.98 & 39.02 & 31.71 & 82 \\
Portugal & 15.79 & 45.92 & 3.06 & 19.39 & 10.20 & 21.43 & 98 \\
\hline \hline
\end{tabular}

Note: US includes few Canadian PhDs. Inbred refers to inbreeding at the national level. Dept refers to the same Department they are working.

Table 3. Bibliometric indices, $\mathrm{PhD}$ origin by country of affiliation

\begin{tabular}{|c|c|c|c|c|c|c|}
\hline \multirow[t]{2}{*}{ Country } & \multirow{2}{*}{$\begin{array}{c}\text { Bibliomet. } \\
\text { Indices }\end{array}$} & \multicolumn{4}{|c|}{ PhD Origin } & \multirow[t]{2}{*}{ Total } \\
\hline & & Inbred & Europe & UK & US & \\
\hline \multirow[t]{3}{*}{ Belgium } & $\mathrm{p} / \mathrm{f}$ & 0.61 & 0.95 & - & 0.70 & 0.66 \\
\hline & $\mathrm{c} / \mathrm{f}$ & 3.64 & 5.69 & - & 7.82 & 4.38 \\
\hline & $\mathrm{h}^{*}$ & 0.23 & 0.38 & - & 0.30 & 0.26 \\
\hline \multirow[t]{3}{*}{ Denmark } & $\mathrm{p} / \mathrm{f}$ & 0.66 & 0.66 & - & 0.64 & 0.67 \\
\hline & $c / f$ & 4.59 & 5.38 & - & 6.17 & 4.97 \\
\hline & $\mathrm{h}^{*}$ & 0.27 & 0.29 & - & 0.32 & 0.29 \\
\hline \multirow[t]{3}{*}{ Greece } & $\mathrm{p} / \mathrm{f}$ & 0.26 & 0.25 & 0.45 & 0.58 & 0.41 \\
\hline & $c / f$ & 0.58 & 0.96 & 1.67 & 3.44 & 1.75 \\
\hline & $h^{*}$ & 0.12 & 0.12 & 0.15 & 0.24 & 0.17 \\
\hline \multirow{3}{*}{ Portugal } & $\mathrm{p} / \mathrm{f}$ & 0.23 & 0.25 & 0.29 & 0.36 & 0.27 \\
\hline & $c / f$ & 0.33 & 0.93 & 1.32 & 1.84 & 0.72 \\
\hline & $h^{*}$ & 0.09 & 0.13 & 0.17 & 0.17 & 0.12 \\
\hline
\end{tabular}

Note: $p / f:$ papers per faculty per year, $c / f$ : citations per faculty per year, $b^{*}$ is a rational $h$-index divided by research age. 
Table 4: Estimated Coefficients under the three methodologies

\begin{tabular}{|c|c|c|c|c|c|c|}
\hline & OOLS & $M$-estimation & QR (median) & OLLS & $M$-estimation & QR (median) \\
\hline & & & & Citations per & & Citations per \\
\hline Dependent Variable & Papers per Year & Papers per Year & Papers per Year & Year & Citations per Year & Year \\
\hline \multirow[t]{2}{*}{$P b D^{U S *}$ Belgium } & $0.957 * * *$ & $0.794 * * *$ & $0.833 * * *$ & $11.921 * *$ & $5.299 * *$ & $4.629 *$ \\
\hline & 3.229 & 5.535 & 4.501 & 2.169 & 5.593 & 1.678 \\
\hline \multirow[t]{2}{*}{$P h D^{U S}$ *Denmark } & $0.618 * *$ & $0.485 * *$ & 0.250 & $4.184 * *$ & $3.030 * *$ & 0.500 \\
\hline & 2.402 & 2.197 & 1.498 & 2.075 & 2.075 & 2.075 \\
\hline PbD ${ }^{U S} *$ Greece & $0.889 * * *$ & $0.655 * * *$ & $0.474 * * *$ & $5.123 * * *$ & $2.228 * *$ & $1.857 * *$ \\
\hline \multirow[t]{2}{*}{$P h D^{U S} *$ Portugal } & $0.452 * * *$ & $0.445 * * *$ & $0.286 * * *$ & $3.501 * *$ & $3.616 * * *$ & 0.813 \\
\hline & 5.346 & 3.261 & 2.643 & 2.505 & 4.465 & 1.354 \\
\hline \multirow[t]{2}{*}{ PhD ${ }^{\text {Inbred } * \text { Belgium }}$} & $0.814 * * *$ & $0.722 * * *$ & $0.643 * * *$ & $6.025 * * *$ & $4.124 * * *$ & $2.250 * * *$ \\
\hline & 9.648 & 10.716 & 4.943 & 7.540 & 9.262 & 4.108 \\
\hline \multirow[t]{2}{*}{ PhD ${ }^{\text {Inbred }} *$ Denmark } & $0.946 * * *$ & $0.841 * * *$ & $0.750 * * *$ & $6.928 * * *$ & $4.662 * * *$ & $3.500 * * *$ \\
\hline & 7.205 & 8.290 & 6.049 & 6.457 & 6.959 & 4.149 \\
\hline PhD ${ }^{\text {Inbred }} *$ Greece & $0.454 * *$ & $0.327 * *$ & $0.222 * *$ & $1.280 * *$ & 1.149 & 0.222 \\
\hline PhD ${ }^{\text {Inbred * }}$ Portugal & 2.949 & 3.275 & 3.805 & 2.249 & 1.657 & 0.490 \\
\hline Standard Error of Regression & 0.88 & 0.89 & 0.91 & 8.38 & 8.64 & 8.95 \\
\hline White Heteroscedasticity $p$-value & 0.77 & & & 0.01 & & \\
\hline
\end{tabular}

Note: $t$-stat below the estimated coefficient, ${ }^{* * *},{ }^{* *}$ and $*$ significance at the $1 \%, 5 \%$ and $10 \%$ respectively. For OLS HAC standard errors, for the $M$-estimation Huber weight, for QR (Quantile Regression) Huber Sandwich standard errors and covariance. The dependent variable is papers per faculty per year and citations per faculty per year. 
Table 5: Relative Productivity (papers per faculty per year and citations per faculty per year)

\begin{tabular}{|c|c|c|c|c|c|c|c|c|}
\hline & \multicolumn{3}{|c|}{ Papers per Faculty per year } & \multirow[b]{2}{*}{ Average } & \multicolumn{3}{|c|}{ Citations Per Faculty Per year } & \multirow[b]{2}{*}{ Average } \\
\hline & OLS & $\begin{array}{l}\text { M-estimation } \\
\text { US PhD }\end{array}$ & QR (median) & & OLS & M-estimation & $\begin{array}{l}\text { QR (median) } \\
\text { US PhD }\end{array}$ & \\
\hline $\mathrm{BE}$ & 1 & 1 & 1 & 1.00 & 1 & 1 & 1 & 1.00 \\
\hline $\mathrm{DK}$ & 0.65 & 0.61 & 0.3 & 0.52 & 0.35 & 0.57 & 0.11 & 0.34 \\
\hline GR & 0.93 & 0.82 & 0.57 & 0.77 & 0.43 & 0.42 & 0.4 & 0.42 \\
\hline PT & 0.47 & $\begin{array}{c}0.56 \\
\text { Inbreeding }\end{array}$ & 0.34 & 0.46 & 0.29 & 0.68 & $\begin{array}{c}0.18 \\
\text { Inbreeding }\end{array}$ & 0.38 \\
\hline $\mathrm{DK}$ & 1 & 1 & 1 & 1.00 & 1 & 1 & 1 & 1.00 \\
\hline $\mathrm{BE}$ & 0.86 & 0.86 & 0.86 & 0.86 & 0.87 & 0.88 & 0.64 & 0.80 \\
\hline GR & 0.48 & 0.39 & 0.3 & 0.39 & 0.18 & 0.25 & 0.06 & 0.16 \\
\hline PT & 0.54 & 0.36 & 0.29 & 0.40 & 0.37 & 0.22 & 0.04 & 0.21 \\
\hline
\end{tabular}

Note: each coefficient is divided by the max coefficient of the regression results of Table 4. Average corresponds to the arithmetic mean of the three estimates. 
Figure 1: Average (OLS) Relative Productivity of US PhD holders depending on the country they are employed

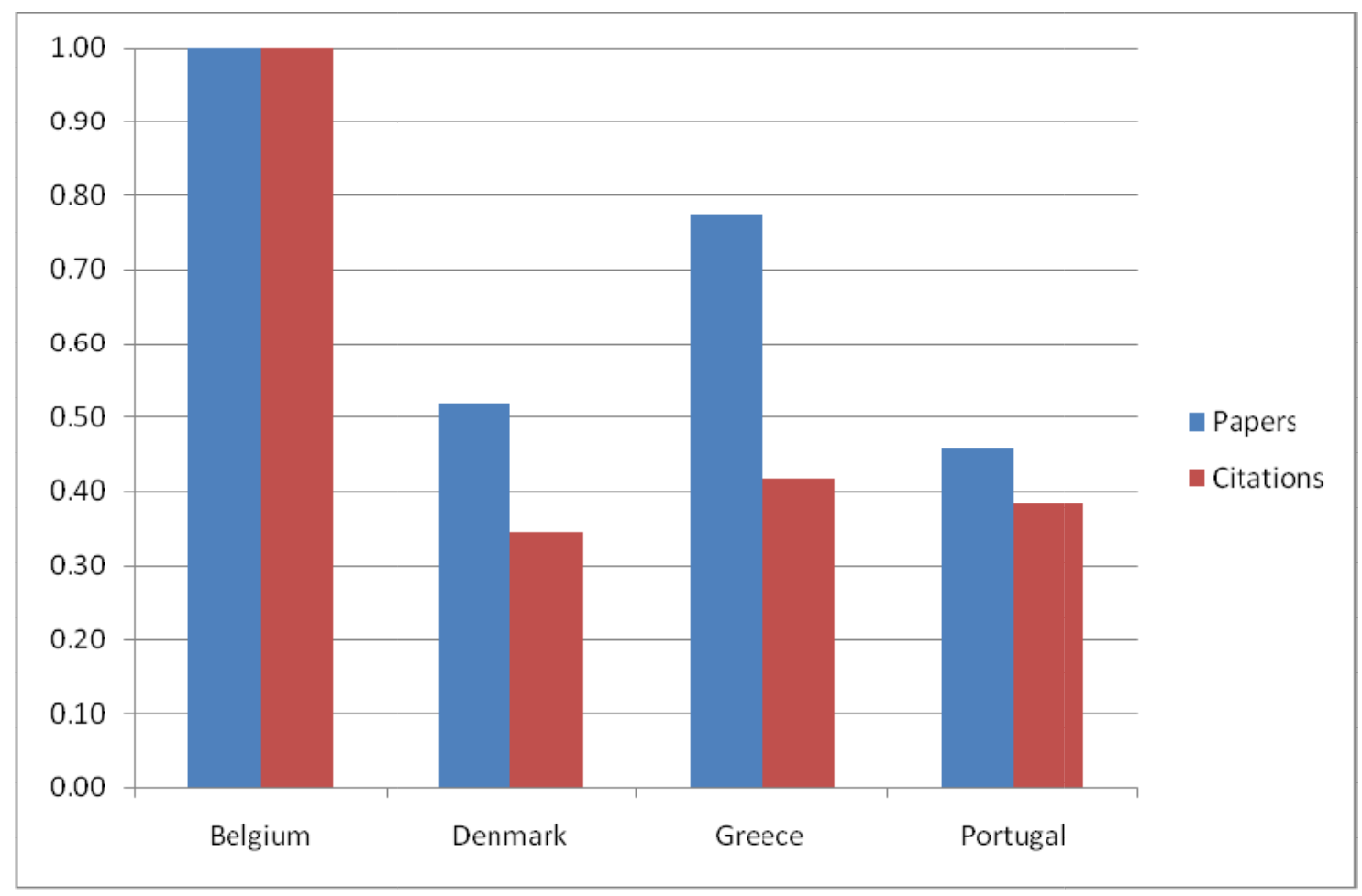

Figure 4: Average (OLS) Relative Productivity of national inbreeders depending on the country they are employed

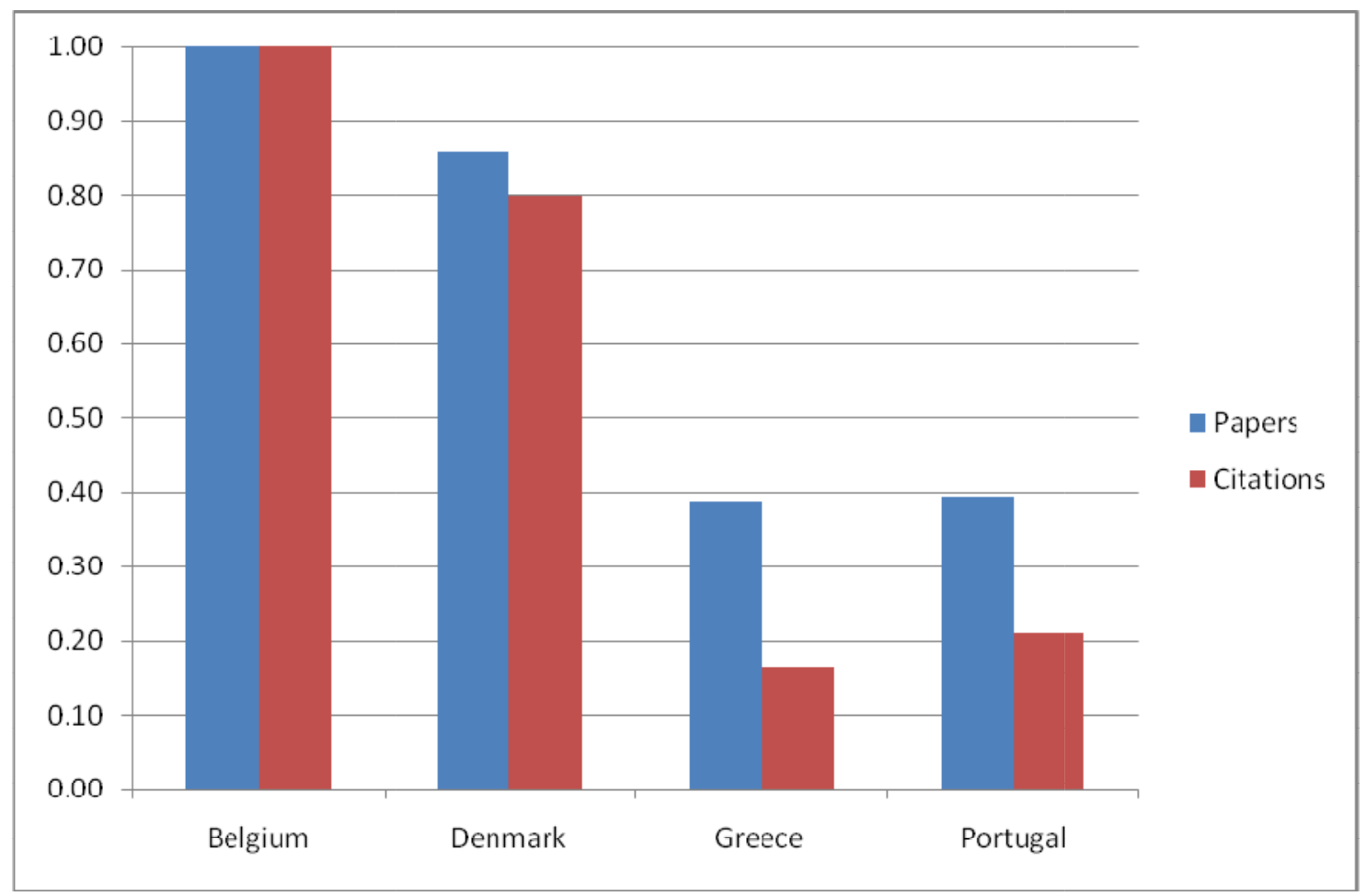


Figure 2: Estimates for various quantiles for papers per faculty per year
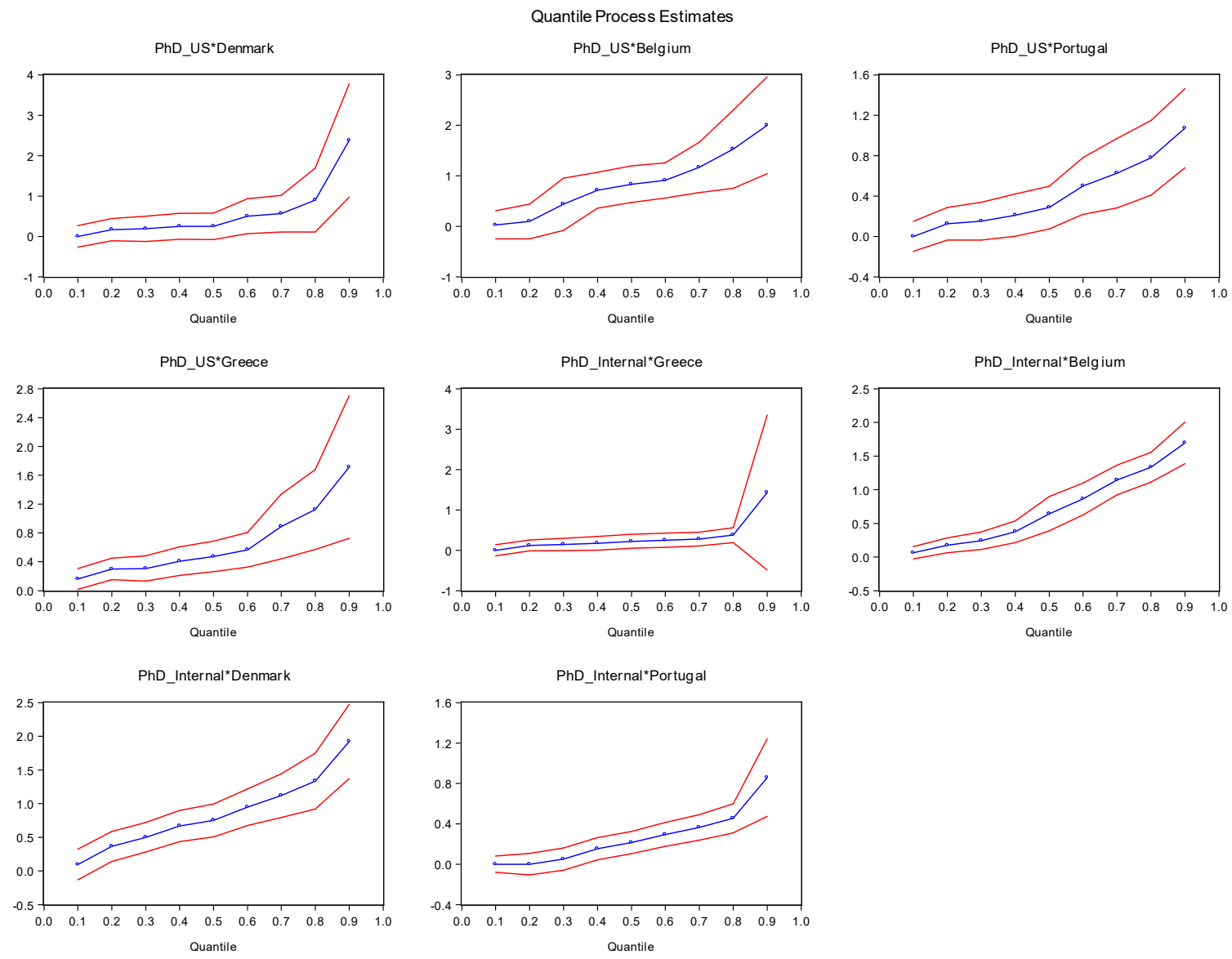
Figure 3: Estimates for various quantiles for citations per faculty per year

Quantile Process Estimates

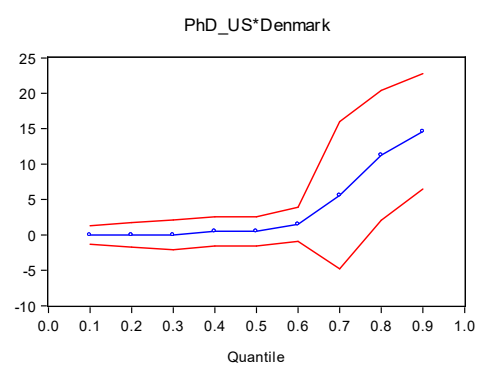

PhD_US*Greece

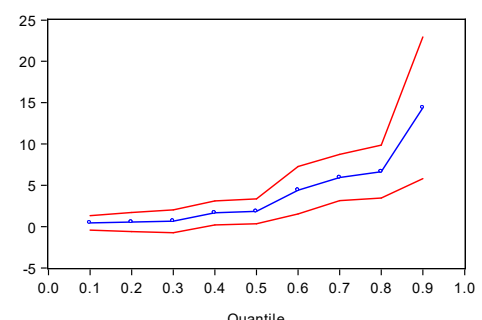

Quantile

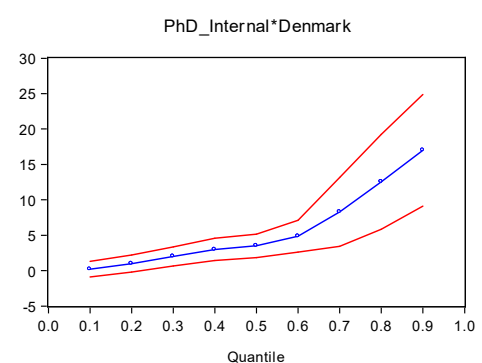

PhD_US*Belgium

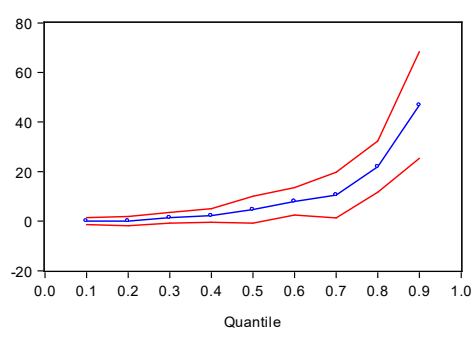

PhD_Internal ${ }^{*}$ Greece

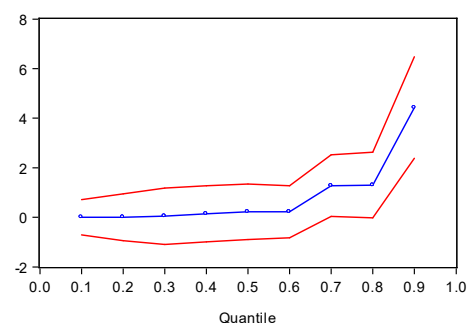

PhD_Internal ${ }^{*}$ Portugal

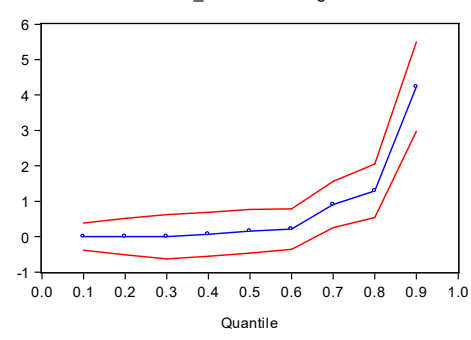

PhD_US*Portugal

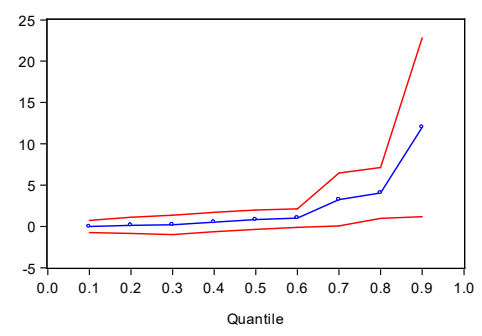

PhD_Internal*Belgium

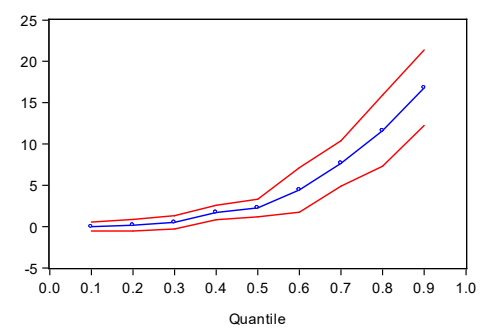

